DOI:

\title{
Perancangan Sistem Informasi Akuntansi Laporan Keuangan Laba Rugi pada Restoran Eatboss Dengan Menggunakan PHP dan MySQL
}

\author{
Zilzi Zade Tazkia ${ }^{1}$
}

Komputerisasi Akuntansi, Universitas Komputer Indonesia,

Jl. Dipati ukur No.112-116 Bandung, Indonesia

Email: zilzizade@mahasiswa.unikom.ac.id

\section{Keywords:}

Accounting informaton systems; restaurant; $P H P$ and MySQL

\author{
Kata Kunci: \\ Sistem Informasi \\ Akuntansi, Restoran, \\ PHP dan MySQL
}

\begin{abstract}
This study aims to design a financial statement accounting information system application for Eatboss restaurant using the PHP and MySQL programming languages. The design of the financial statement accounting information system application in Eatboss restaurant using PHP and MySQL is done using library research and survey methods. At this time, it is necessary to prepare financial statements of profit and loss for each company, including restaurants, to find out the profit or loss gained during the specified period of the company. So that the company can determine the next decision for the continuity of better company activities. The design of fiinancial statement accounting information system in Eatboss reataurant using PHP and MySQL can facilitate omapnies in managing financial reports. With the maximum use of the financial statement accounting information system design at Eatboss restaurant using PHP and MySQL, it is expected that the company can more quickly and easily manage its financial statements based on accounting standards.
\end{abstract}
Abstrak
Penelitian ini bertujuan untuk merancang aplikasi sistem informasi akuntansi laporan keuangan laba rugi pada restoran Eatboss dengan menggunakan bahasa pemrograman PHP dan MySQL. Perancangan aplikasi sistem informasi akuntansi laporan keuangan laba rugipada restoran Eatboss dengan menggunakan PHP dan MySQL ini dilakukan dengan menggunakan metode penelitian kepustakaan dan survei. Di saat seperti sekarang ini perlu adanya penyusunan laporan keeuangan laba rugi pada setiap perusahaan termasuk restoran untuk mengetabui laba atau rugi yang diperoleh selama periode terentu dari perusabaan tersebut. Agar perusabaan dapat menentukan keputusan selanjutnya guna kelangsungan kegiatan perusabaan yang lebih baik.Perancangan sistem informasi akuntansi laporan keuangan laba rugipada restoran Eatboss dengan menggunakan PHP dan MySQL ini dapat mempermudah perusahaan dalam mengelola laporan keuangan. Dengan adanya penggunaan yang maksimal dari perancangan sistem informasi akuntansi laporan keuangan laba rugi pada restoran Eatboss dengan menggunakan PHP dan MySQL ini dibarapkan perusahaan dapat lebih cepat dan mudah dalam mengelola laporan keuangannya berdasarkan standar akuntansi. 


\section{Pendahuluan}

\section{Latar Belakang}

Pada saat sekarang ini dibuthkan sistem yang bisa menunjang kegiatan berbisnis. Salah satunya adalah bisnis dibidang kuliner. Suatu restoran harus memiliki sistem yang baik untuk mengelola restoran tersebut dengan baik pula. Salah satunya adalah sistem untuk mengelola laporan keuangan daripada restoran tersebut.

Berdasarkan hasil wawancara dengan captain perusahaan yaitu bapak Agum pada hari Selasa,16 April 2016 adalah pada proses pembuatan laporan laba rugi sudah memakai sistem yang berjalan,yakni sistem POS. Tetapi pada sistem tersebut bisa saja ditemukan kekurangan. Kekurangan tersebut ialah jika situasi restoran sedang ramai, maka sistem yang digunakan error.

Pada restoran Eatboss pencatatan pesanan dilakukan manual terlebih dahulu lalu diinput ke sistem. Selanjutnya kasir akan melakukan pembukuan dan diserahkan ke bagian akunting. Pada perusahaan laporan keuangan laba rugi memiliki fungsi yaitu meninjau pendapatan dan bebanbeban yang telah dikeluarkan selama periode tertentu lalu perusahaan dapat menyimpulkan apakah usahanya memperoleh laba atau rugi.

Berdasarkan permasalahan-permasalah yang peneliti jumpai maka peneliti mengambil judul "Perancangan Sistem Informasi Akuntansi Laporan Keuangan Laba Rugi pada Eatboss menggunakan PHP dan database MySQL". Peneliti menggunakan bahasa pemrograman PHP agar bisa berjalan di web. Menggunakan database MySQL dikarenakan tidak berbayar dan mudah digunakan.

1. Rumusan Masalah

A. Bagaimana sistem yang digunakan untuk membuat laporan keuangan laba rugi pada perusahaan.

B. Bagaimana merancang sistem informasi akuntansi laporan keuangan laba rugi pada Eatboss menggunakan PHP dan MySQL.

2. Batasan Masalah
A. Akuntansi laporan keuangan laba rugi menurut standar laporan keuangan akuntansi menggunakan PHP dan MySQL, peneliti membatasi hanya pada bagian captain, kasir dan bagian akunting.
B. Perancangan sistem informasi akuntansi laporan keuangan laba rugi pada restoran Eatboss menurut standar laporan keuangan akuntansi menggunakan aplikasi PHP dan MySQL.
C. Peneliti tidak membuat laporan harga pokok penjualan.

3. Tujuan Penelitian

A. Untuk mengetahui sistem yang digunakan untuk membuat laporan keuangan laba rugi pada Eatboss.

Untuk perancangan sistem informasi akuntansi laporan keuangan laba rugi pada Restoran Eatboss menggunakan PHP dan database MySQL. 


\section{Kerangka Teoritis Dan Pengembangan Hipotesis}

\section{Sistem}

Definisi dari sistem adalah sistem merupakan suatu jaringan kerja dari prosedur-prosedurnya yang saling berhubungan, berkumpul bersama-sama untuk melakukan suatu kegiatan atau untuk menyelesaikan suatu sasaran tertentu[1].

\section{Informasi}

Pengertian dari informasi yaitu informasi adalajh data yang diorganisasikan ke dalam bentuk yang sesuai dengan kebutuhan seseorang, staf, manajer, atau orang lain di dalam suatu organisasi atau perusahaan[2].

\section{Akuntansi}

Pengertian dari akuntansi yaitu akuntansi merupakan suatu seni pencatatan, penggolongan, dan peringkasan dengan cara yang informatif dan diukur dalam bentu mata uang, atas transaksitransaksi atau kejadian-kejadian keuangan perusahaan dan interpretasi hasilnya[3].

\section{Sistem Informasi Akuntansi}

Pengertian sistem informasi akuntansi adalah Sistem informasi akuntansi merupakan suatu komponen yang mengumpulkan menggolongkan, mengolah, menganalisa, dan mengkomunikasikan informasi keuangan yang relevan untuk pengambilan keputusan kepada pihak luar[4].

\section{Laporan Keuangan Laba Rugi}

Laporan keuangan laba rugi yaitu suatu laporan yang disusun secara sistematis berdasarkan standar akuntansi yang memuat tentang hasil operasi selama atau tahun atau periode akuntansi. Laporan ini menunjukkan sumber dari mana penghasilan diperolah serta beban yang dikeluarkan sebagai beban perusahaan, secara sistematis merupakan laporan tentang penghasilan, beban-beban, dan laba atau rugi[5].

\section{PHP}

PHP adalah kependekan dari PHP:Hyper Text Preprocessor (rekursif, mengikuti gaya penamaan di *nix),merupakan bahasa utama script server-side yang disisipkan pada HTML yang dijalankan di server, dan juga bisa digunakan untuk membuat aplikasi desktop[6]. 


\section{MySQL}

MySQL merupakan software RDMS (atau server database) yang dapat mengelola database dengan sangat cepat, dapat menampung data dalam jumlah sangat besar, dapat diakses oleh banyak user (multi-user), dan dapat melakukan suatu proses secara sinkron atau berbarengan (multithreaded) [7].

\section{Metode}

\section{Unit Analis} Bandung.

Peneliti meneliti unit analisis pada restoran Eatboss yang berada di Jln. Ir. H. Juanda no.72,

\section{Populasi dan Sampel}

Populasi yang diteliti dalam penelitian ini adalah laporan keuangan. Sedangkan sampel yang peneliti teliti adalah laporan keuangan selama periode tertentu.

\section{Objek Penelitian}

Objek penelitian yang peneliti lakukan adalah merancang sistem informasi akuntansi laporan keuang laba rugi pada restoran Eatboss denga menggunakan bahasa pemrograman PHP dan database MySQL.

\section{Desain Penelitian}

Desain penelitian yang peneliti desain yaitu dengan judul perancangan sistem informasi laporan keuangan laba rugi, yang bertujuan untuk memperoleh nilai matakuliah metodologi penelitian.

\section{Metode Penelitian}

Didalam penelitian ini, peneliti menggunakan dua jenis metode penelitian. Yaitu metode penelitian deskrptif dan metode sruvei.

\section{Metodologi Pengembangan Sistem}

Dapat disimpulkan oleh peneliti bahawa metodologi pengembangan sistem adal konsep atau suatu cara untuk mengembangkan suatu sistem informasi.

\section{Model Pengembangan Sistem}

Pada penelitian ini model pengembangan sistem yang peneliti gunakan adala metode pengembangan iterasi. 

Laporan Keuangan Laba Rugi pada Restoran Vol. 04 No. 01. Juni 2019: Hal 426-440 Eatboss Dengan Menggunakan PHP dan P-ISSN: 2252-9853 MySQL

E-ISSN: $2656-808 \mathrm{X}$

DOI:

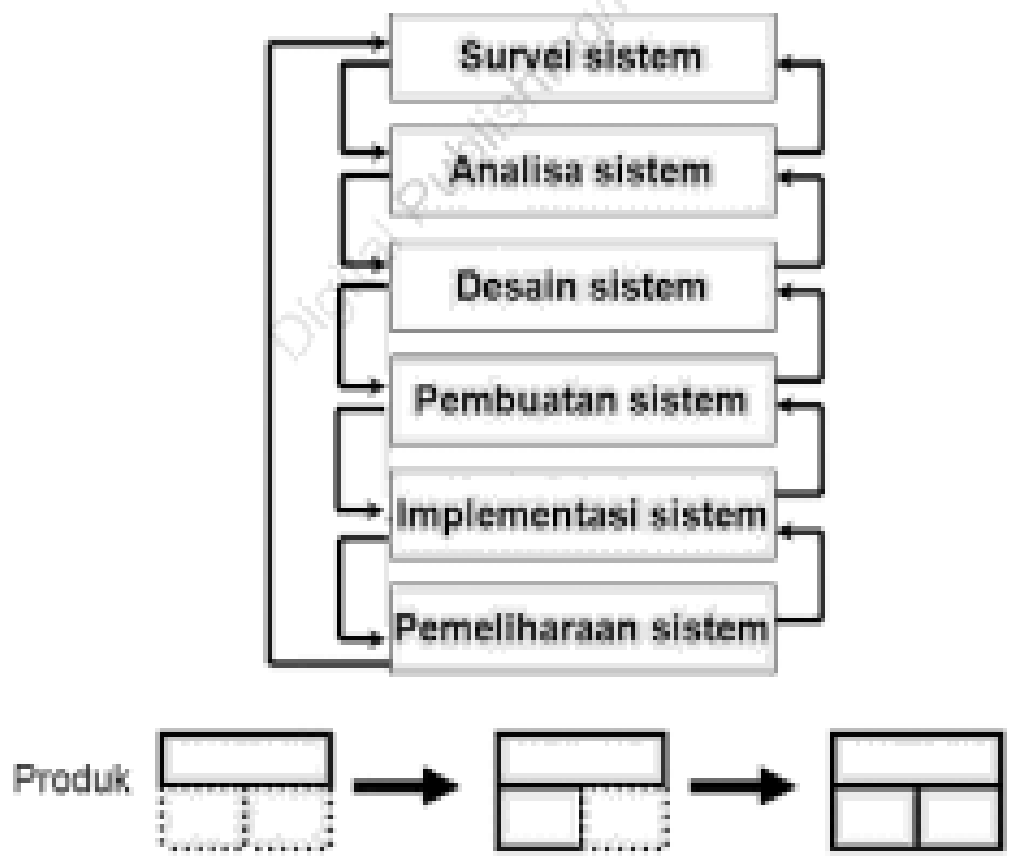

Gambar 1. Model iterasi menurut I Gusti Ngurah Suryantara, S. Kom, M.Kom

Pengertian iterasi adalah Iterasi (Iteration) suatu tahapan proses yang dilaksanakan berulangulang sampai mendapatkan hasil yang diinginkan[8].

\section{Lokasi Penelitian}

Peneliti melaksanakan penelitian di restoran Eatboss yang terletak di Jln. Ir. H. Juanda no.72 Bandung sebagai kantor pusat. Bidang perusahaan ini adalah pada kuliner dan merupakan sebuah restoran

\section{Hasil Dan Pembahasan}

\section{Perancangan Sistem Usulan}

Perancangan sistem yang digunakan adalah dengan menggunakan ERD (Entity Relationship Diagram). 
Nama penulis : Zilzi Zade Tazkia

Judul : Perancangan Sistem Informasi Akuntansi Laporan Keuangan Laba Rugi pada Restoran Eatboss Dengan Menggunakan PHP dan MySQL
Jurnal @ is The Best Vol. 04 No. 01. Juni 2019: Hal 426-440

P-ISSN: 2252-9853

E-ISSN: 2656-808X

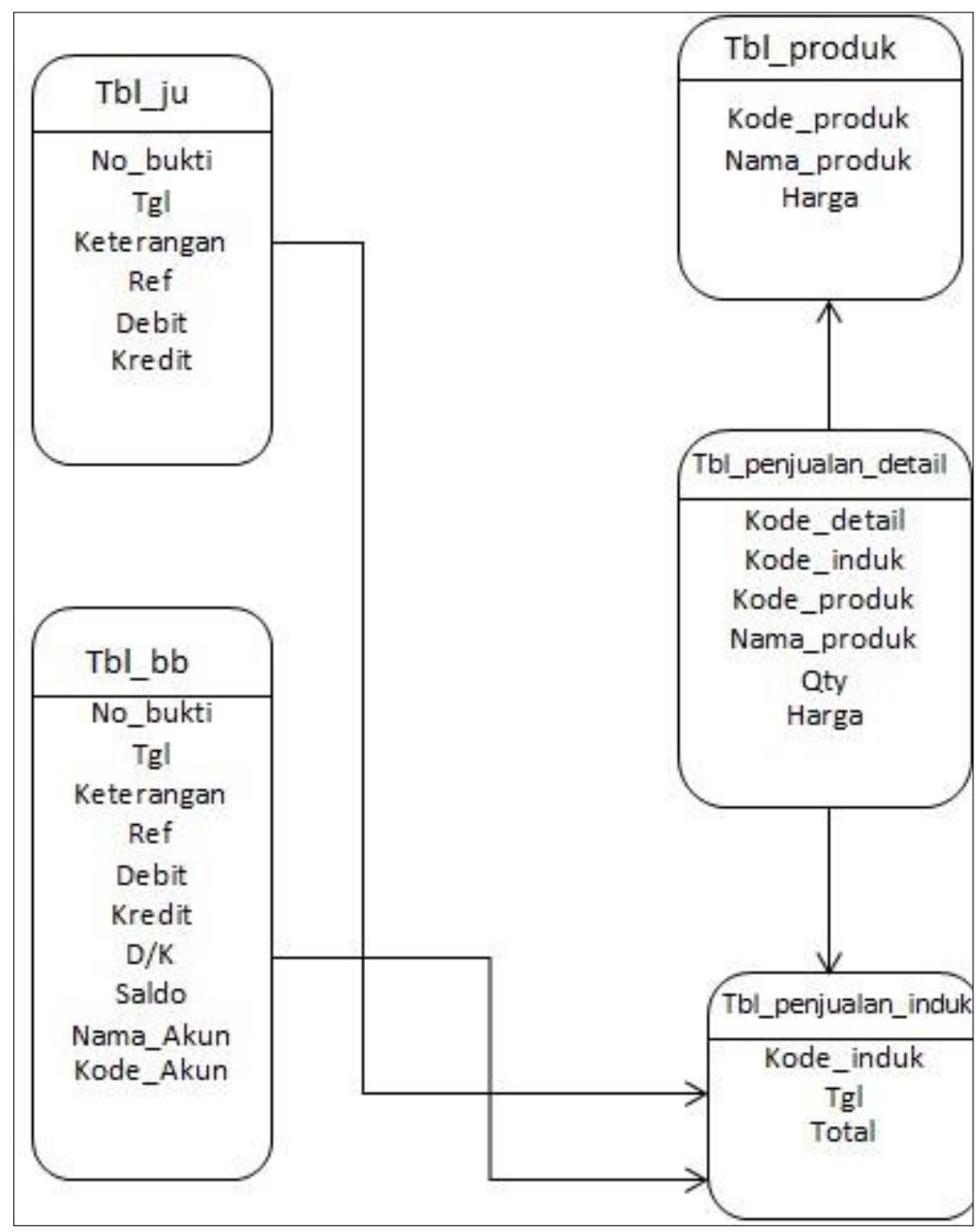

Gambar 2. ERD

Perancangan ERD dilakukan untuk menjelaskan hubungan data-data pada sebuah basis data. Pada gambar 2 diatas telah dibuat pemodelan ERD dengan tujuan memudahkan penjelasan datadata yang saling berhubungan pada basis data.

\section{Peracangan Struktur Aplikasi}



Laporan Keuangan Laba Rugi pada Restoran Vol. 04 No. 01. Juni 2019: Hal 426-440 Eatboss Dengan Menggunakan PHP dan P-ISSN: 2252-9853 MySQL

\subsection{Akun dan Kode Akun Usulan}

Gambar 3. Kode Akun dan Nama Akun

\begin{tabular}{|c|c|}
\hline Kode Akin & Nama Aklin \\
\hline 111 & Kas \\
\hline 112 & Persediani bahan bakt \\
\hline 113 & Persediann bahan penolong \\
\hline 114 & Persedianis produk dalam proses \\
\hline 411 & Penipulail \\
\hline 501 & Barang dalam proses-BBB \\
\hline 502 & Barang dalamproses-BTKL \\
\hline 503 & Barang dalam proses-BOP \\
\hline 504 & BOP sesungogulinga \\
\hline 511 & Bebailgail \\
\hline 611 & Bebail listilik \\
\hline 612 & Bebanadm dan umum \\
\hline
\end{tabular}

\subsection{Struktur Login}

Berikut adalah rancangan struktur aplikasi yang dirancang penulis:

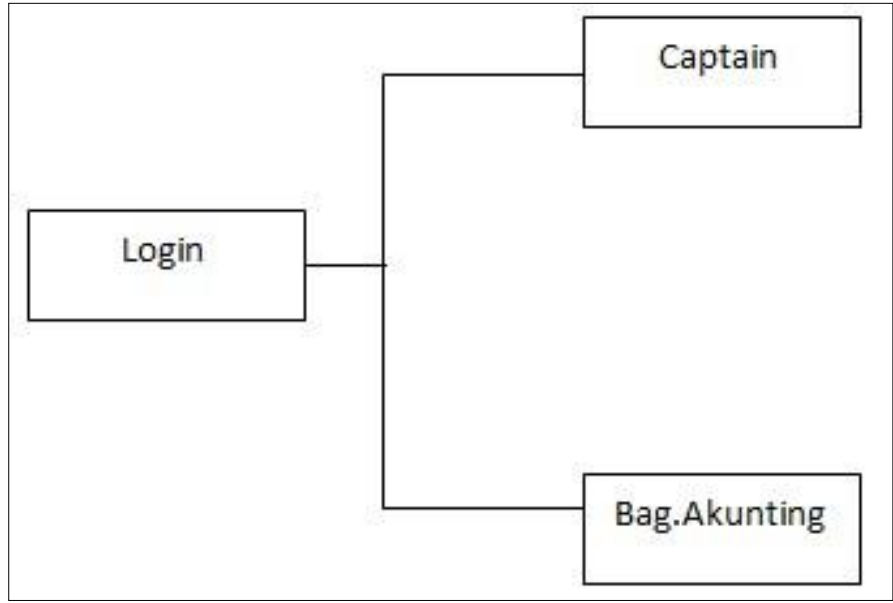

Gambar 4. Struktur menu utama

Menu login dapat diakses oleh captain dan bagian akunting. Menu login diakses dengan cara memasukan username dan password. 
Nama penulis : Zilzi Zade Tazkia

Judul : Perancangan Sistem Informasi Akuntansi Laporan Keuangan Laba Rugi pada Restoran Eatboss Dengan Menggunakan PHP dan MySQL
Jurnal @ is The Best Vol. 04 No. 01. Juni 2019: Hal 426-440

P-ISSN: 2252-9853

E-ISSN: 2656-808X

\subsection{Struktur Menu pada Captain}

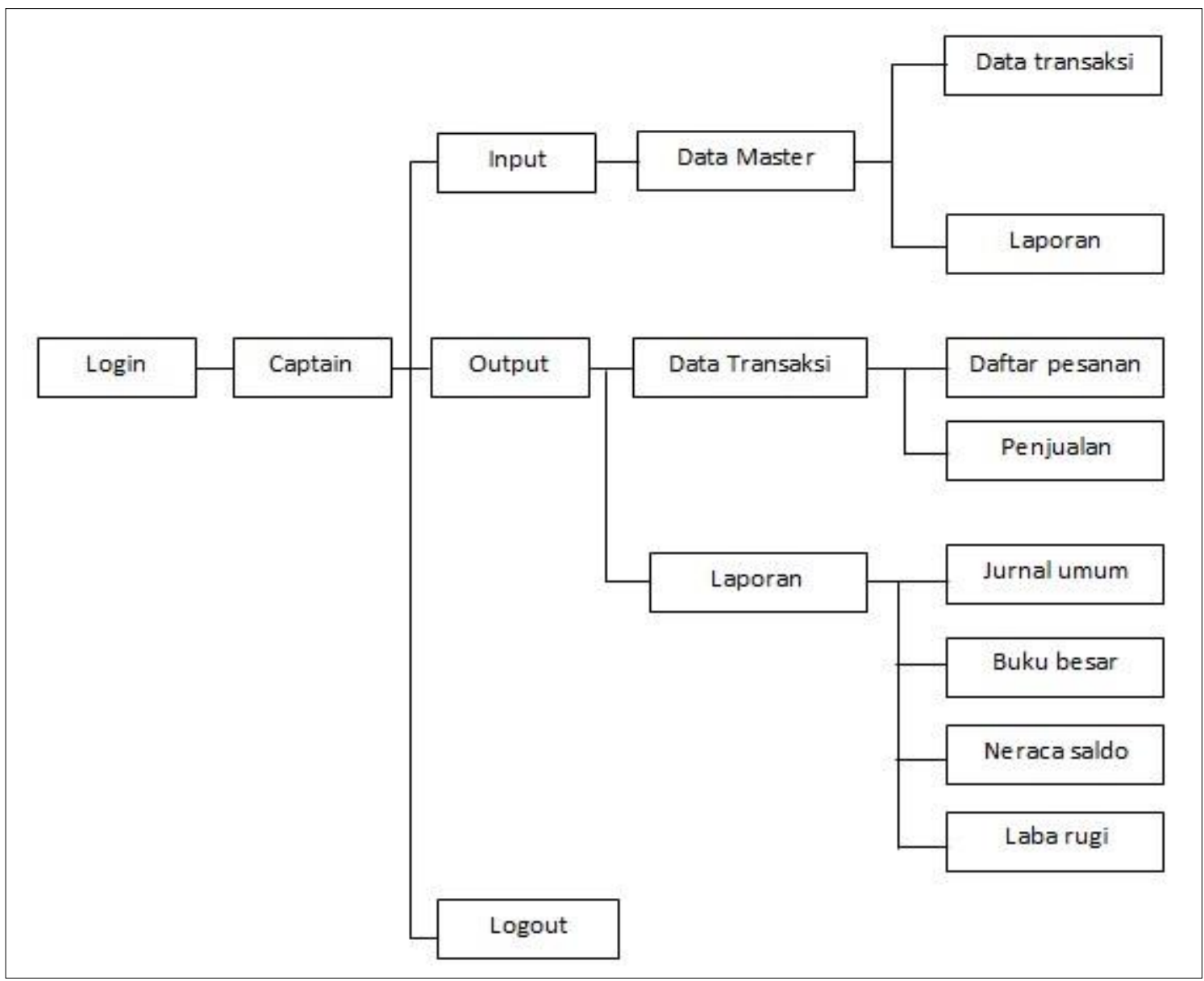

Gambar 5. Struktur menu captain

Menu pada captain dapat mengakses data transaksi dan laporan. Captain juga dapat mengakses laporan keuangan berupa jurnal umum, buku besar, neraca saldo, dan laba rugi.

\subsection{Struktur Menu pada Bagian Akunting}

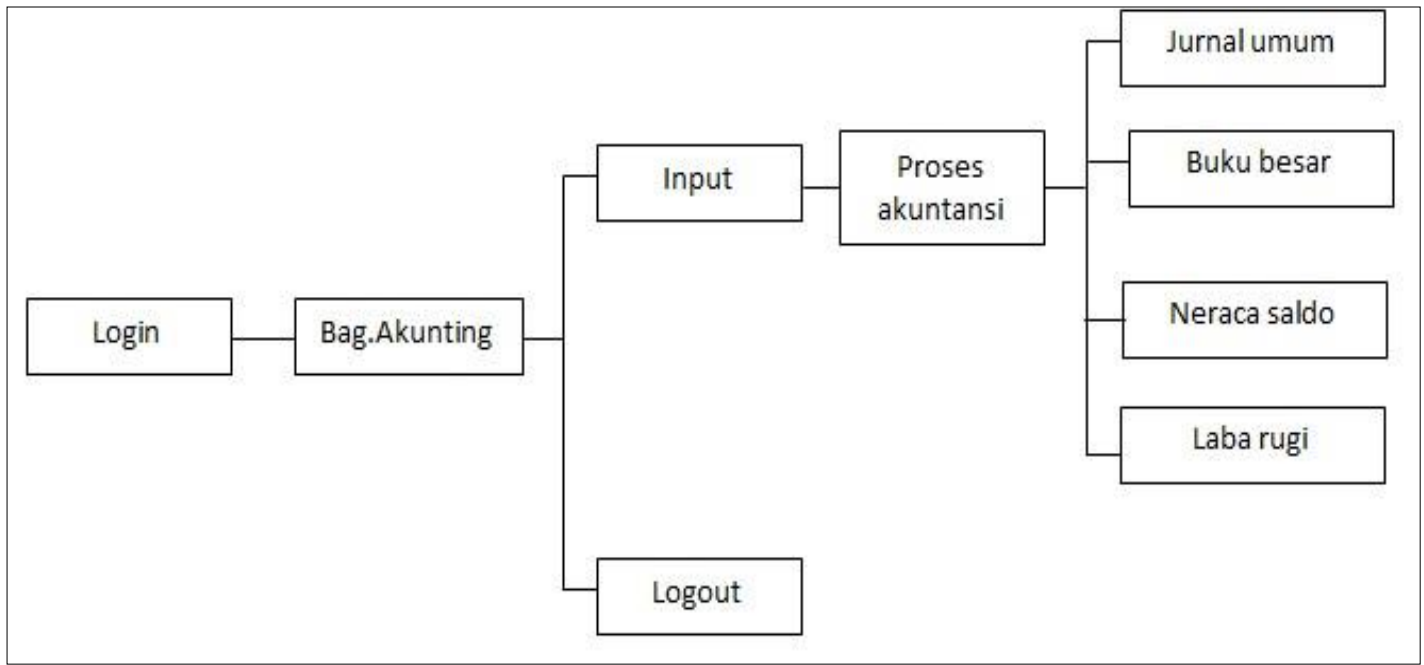


Nama penulis : Zilzi Zade Tazkia

Judul : Perancangan Sistem Informasi Akuntansi Laporan Keuangan Laba Rugi pada Restoran Eatboss Dengan Menggunakan PHP dan MySQL
Jurnal @ is The Best Vol. 04 No. 01. Juni 2019: Hal 426-440

P-ISSN: 2252-9853

E-ISSN: $2656-808 \mathrm{X}$

Gambar 6. Srtuktur menu bag.akunting

Menu pada bag.akunting hanya dapat mengakses laporan keuangan berupa jurnal umum, buku besar, neraca saldo dan laba rugi. Akunting juga bisa meng input proses akuntansi.

\subsection{Pembuatan Rancangan User Interface}

Berikut merupakan rancangan antar muka yang dirancang oleh penulis:

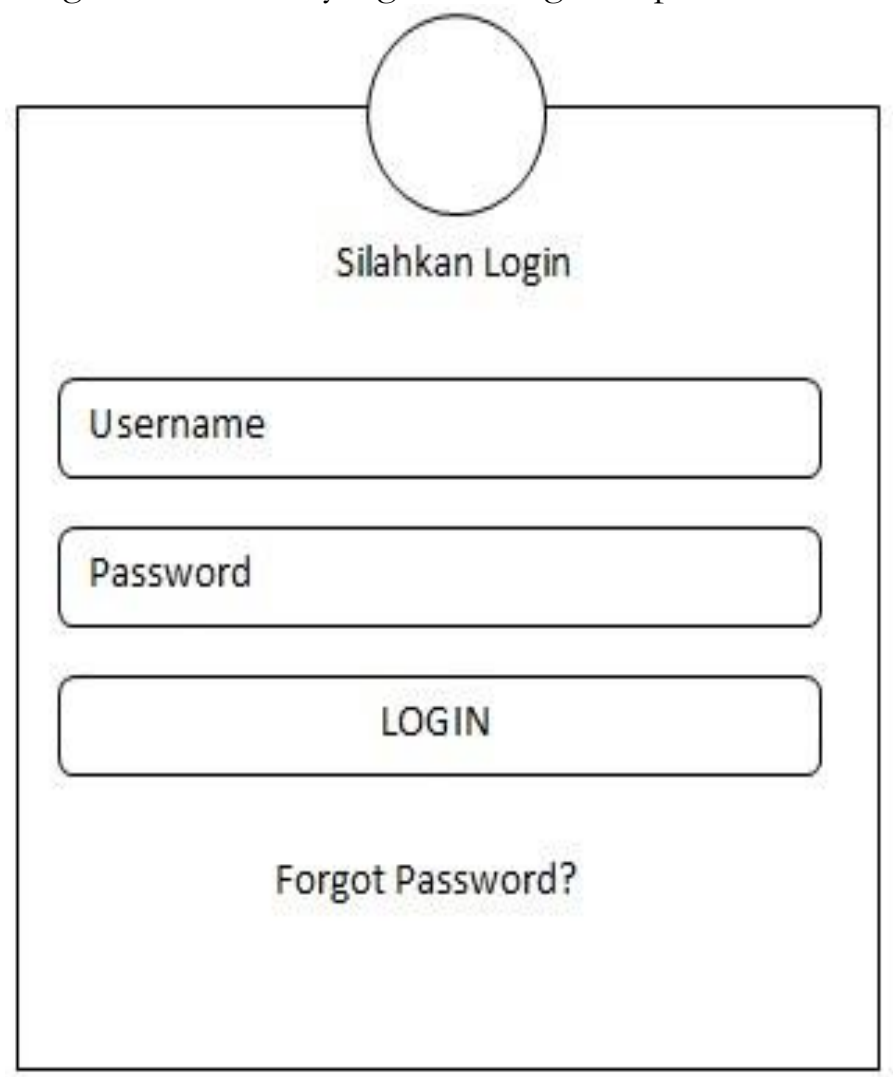

Gambar 7. Perancangan antar muka pada login

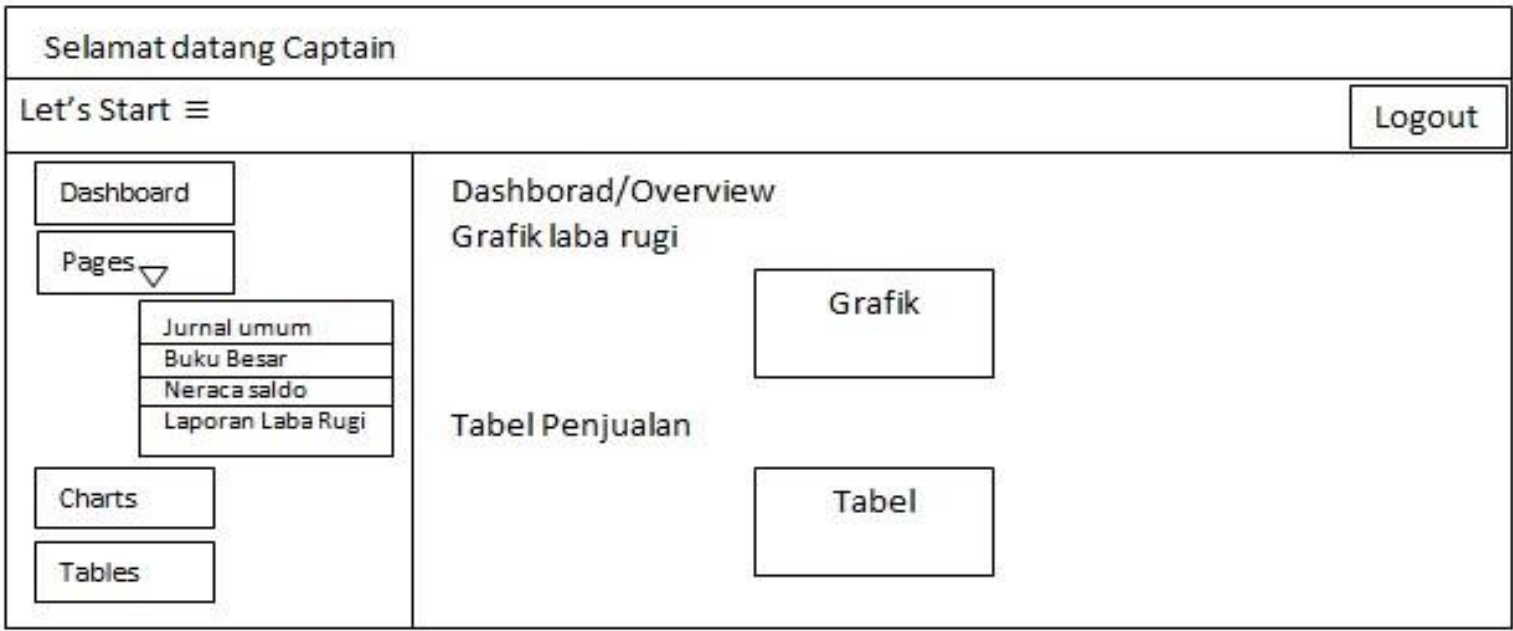

Gambar 8. Perancangan antar muka pada menu captain 
Nama penulis : Zilzi Zade Tazkia

Judul : Perancangan Sistem Informasi Akuntansi Laporan Keuangan Laba Rugi pada Restoran Eatboss Dengan Menggunakan PHP dan MySQL
Jurnal @ is The Best Vol. 04 No. 01. Juni 2019: Hal 426-440

P-ISSN: 2252-9853

E-ISSN: 2656-808X

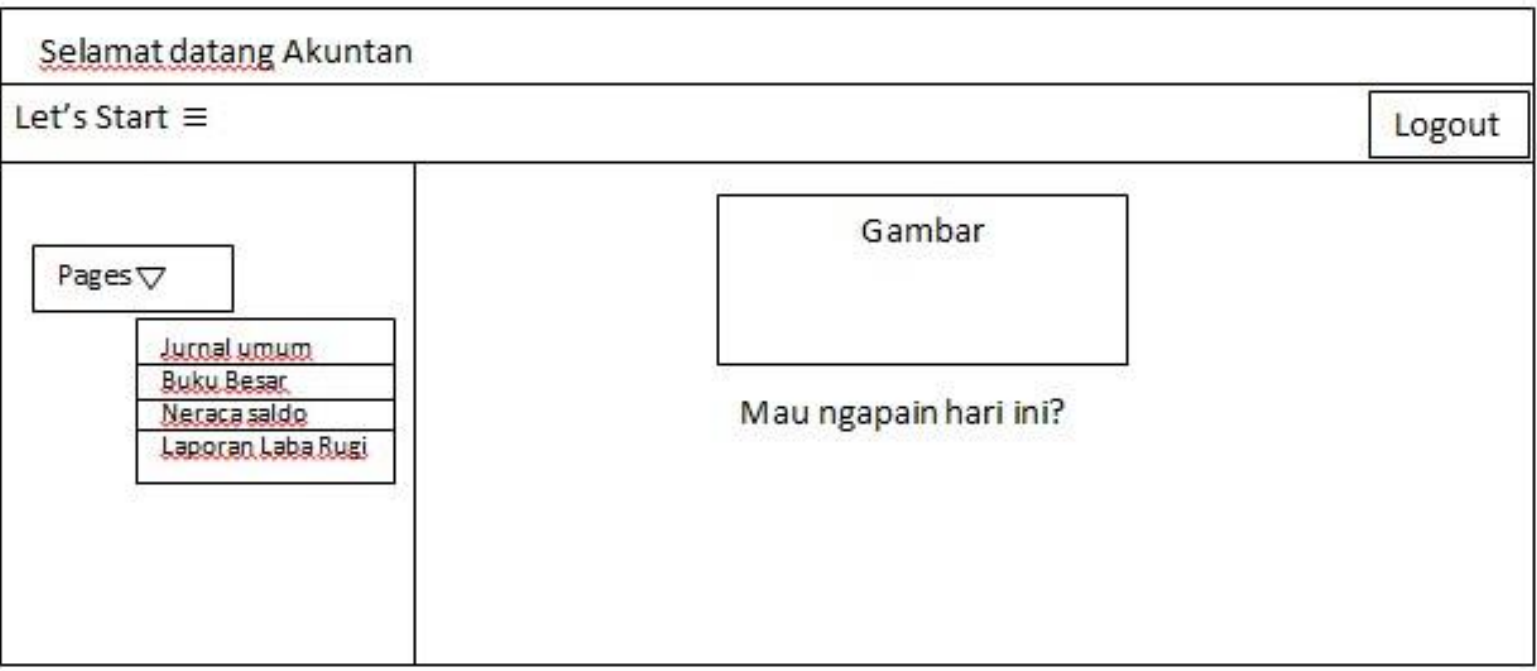

Gambar 9. Perancangan antar muka pada menu bag.akunting

\subsection{Tampilan}

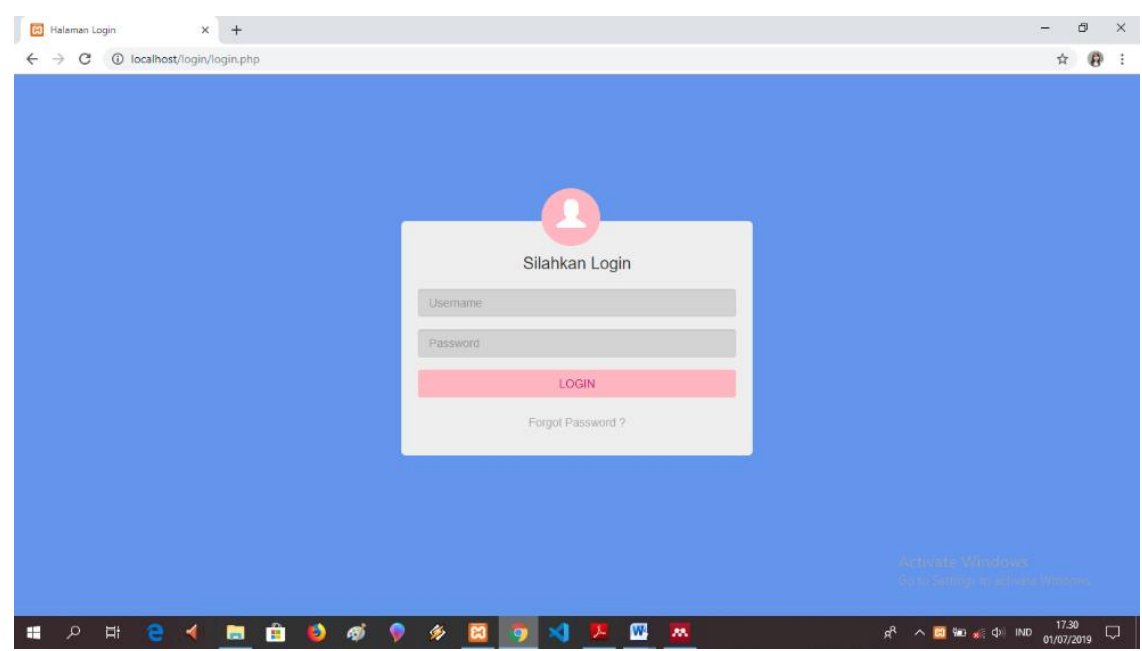


Nama penulis : Zilzi Zade Tazkia

Judul : Perancangan Sistem Informasi Akuntansi Laporan Keuangan Laba Rugi pada Restoran Eatboss Dengan Menggunakan PHP dan MySQL
Jurnal @ is The Best Vol. 04 No. 01. Juni 2019: Hal 426-440

P-ISSN: 2252-9853

E-ISSN: 2656-808X

Gambar 10. Tampilan pada login
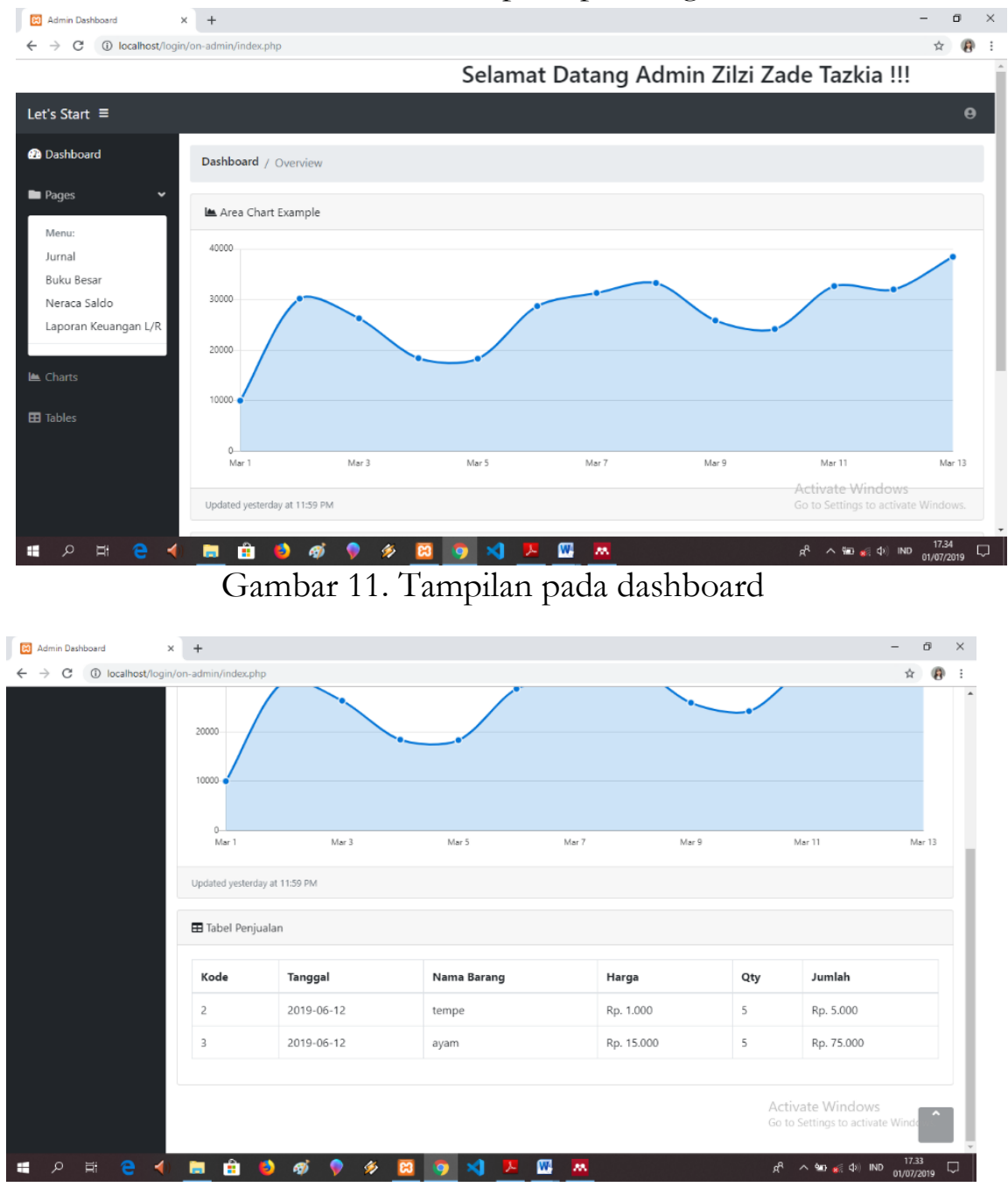

Gambar 12. Tampilan pada dashboard

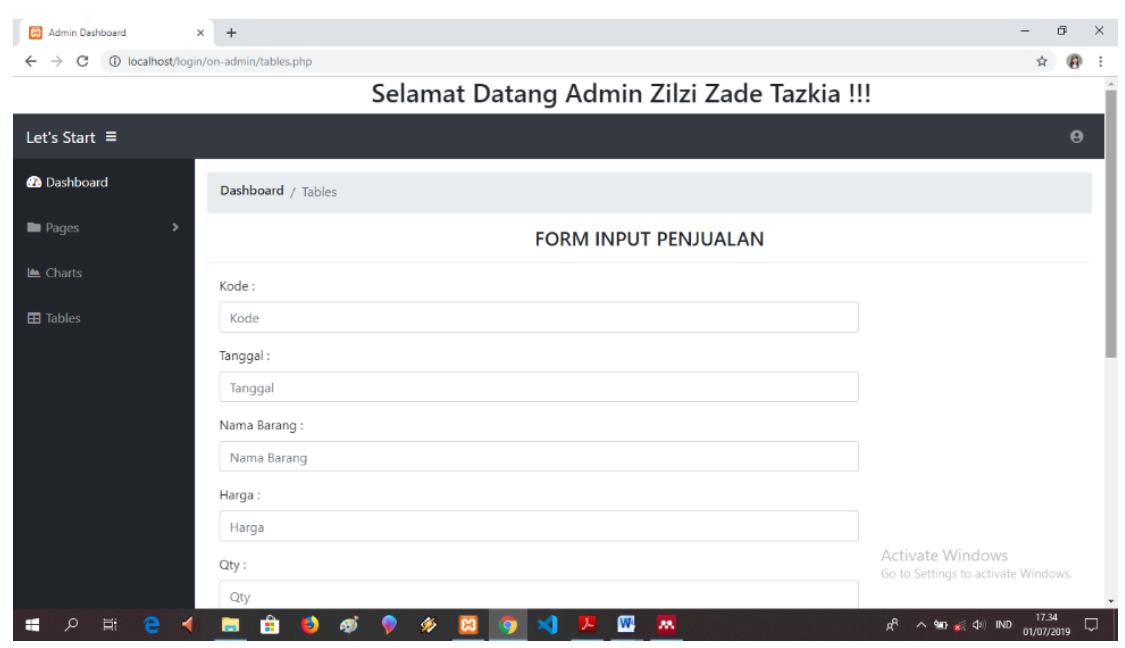

Gambar 13. Tampilan form input penjualan 
Nama penulis : Zilzi Zade Tazkia

Judul : Perancangan Sistem Informasi Akuntansi Laporan Keuangan Laba Rugi pada Restoran Eatboss Dengan Menggunakan PHP dan MySQL
Jurnal @ is The Best Vol. 04 No. 01. Juni 2019: Hal 426-440

P-ISSN: 2252-9853

E-ISSN: 2656-808X

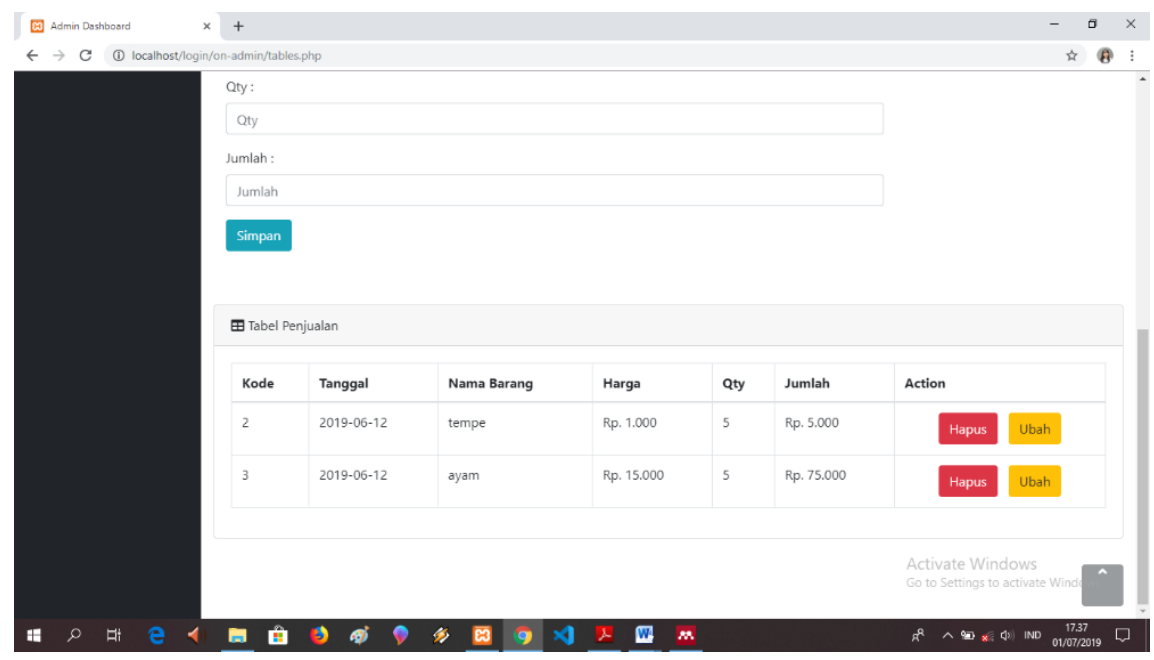

Gambar 14. Tampilan tabel penjualan

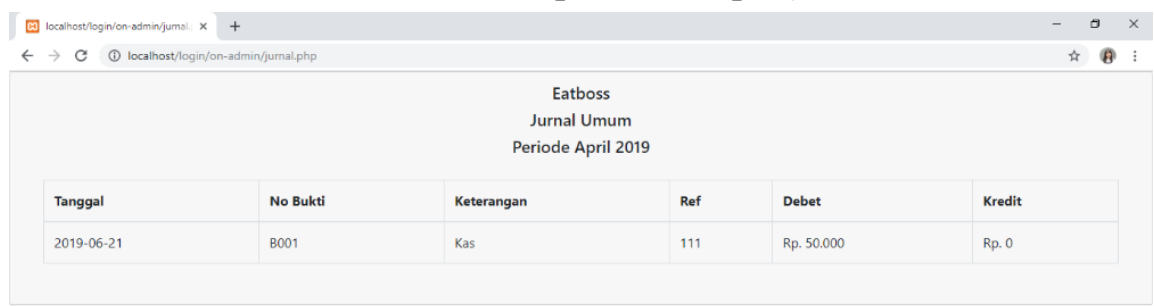

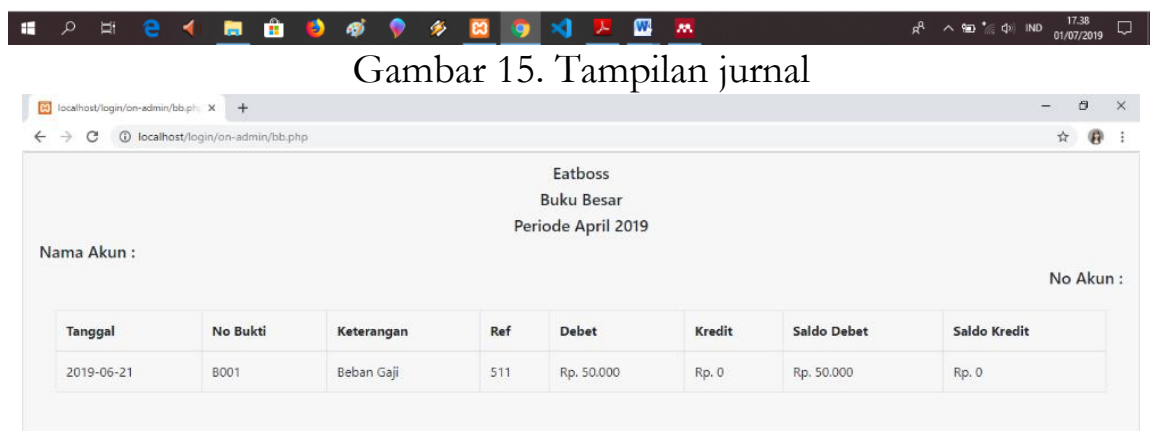


Nama penulis : Zilzi Zade Tazkia

Judul : Perancangan Sistem Informasi Akuntansi Laporan Keuangan Laba Rugi pada Restoran Eatboss Dengan Menggunakan PHP dan MySQL
Jurnal @ is The Best Vol. 04 No. 01. Juni 2019: Hal 426-440

P-ISSN: 2252-9853

E-ISSN: 2656-808X

Gambar. 16. Tampilan buku besar

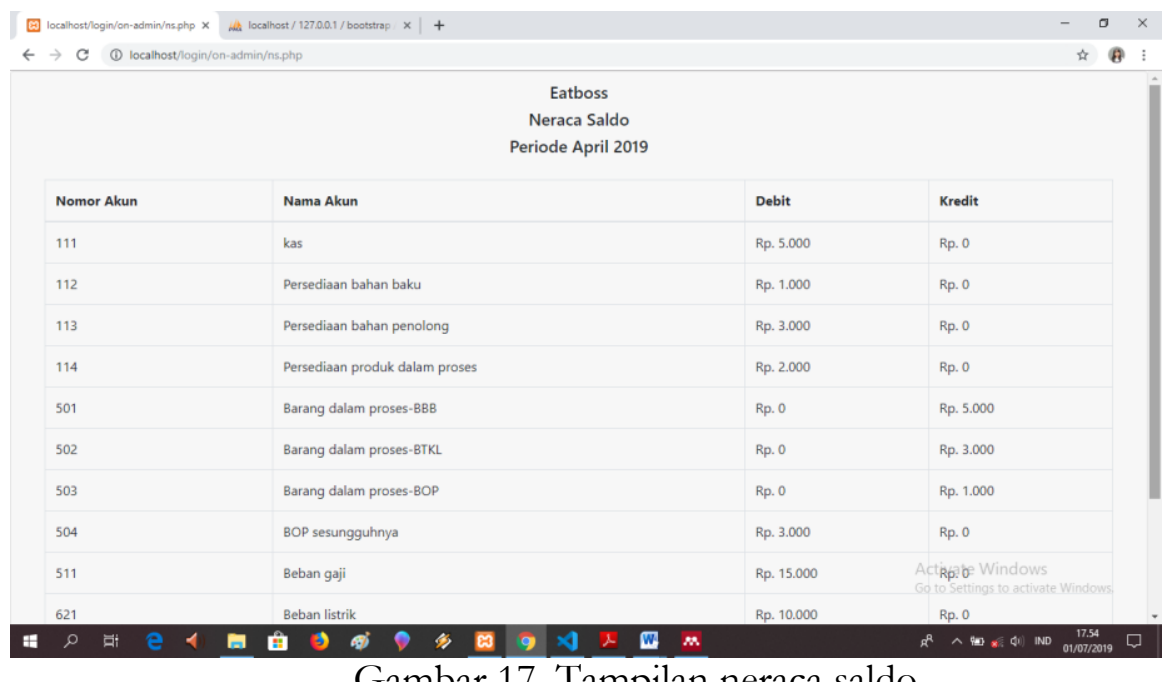

Gambar 17. Tampilan neraca saldo

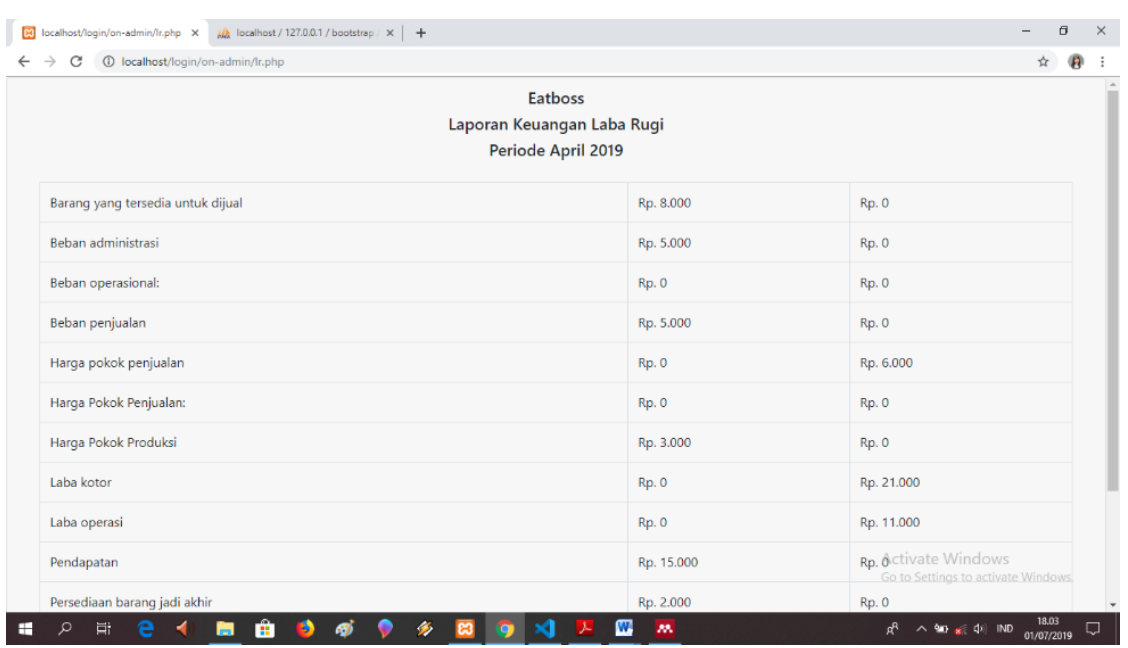

Gambar 18. Tampilan laporan keuangan laba rugi 


\section{Penutup}

\section{Simpulan}

A. Pada restoran Eatboss proses pencatatan sudah terkomputerisasi dan memakai sistem. Tetapi sistem yang digunakan terkadang error dikarenakan banyaknya pencatatan yang harus diinput kedalam sistem tersebut. Untuk pencatatan makanan pun sebenarnya sudah bisa menggunakan smartphone, tetapi dikarenakan pegawai yang masih belum terbiasa menggunakan smartphone maka masih diacatat manual. Laporan keuangannya pun belum menggunakan standar akuntansi.

B. Untuk memeperbaiki masalah tersebut, maka peneliti membuat rancangan sebuah sistem informasi akuntansi laporan keuangan laba rugi menggunakan bahasa pemrograman PHP dan database MySQL. Perancangan sistem informasi akuntansi keuangan laba rugi ini dimaksudkan untuk mempermudah pengguna agar dapat mengetahui laba atau rugi dari perusahaan ersebut. Model yang digunakan pada peracangan sistem ini adalah dengan ERD. Diharapakan dengan adanya aplikasi ini dapat mempermudah dalam menyusun laporan keuangan laba rugi dengan standar akuntansi.

C. Diharapkan dengan adanya aplikasi ini bisa memudahkan penyusunan laporan keuangan laba rugi yang sesuai dengan standar akuntansi. Aplikasi ini juga diharapkan bisa membantu pengguna dalam penyusunan laporan keuangan laba rugi dengan kemungkinan kesalahan yang rendah.

\section{Saran}

A. Untuk aplikasi ini berjalan dengan baik pada saat digunnakan, membutuhkan users yang mengerti dengan pengoperasian komputer. Dibutuhkan juga koneksi dari wifi/modem agar proses penginputan dapat berjalan dengan baik tidak terkendala.

Pada aplikasi ini dapat dikembangkan lebih baik lagi dari aplikasi yang diranacang saat ini. Pada segi akuntansi, dapat dikembangkan dengan menambahkan perhitungan harga pokok produksi. Lalu untuk segi sistem, aplikasi ini bisa dikembangkan lebih jauh lagi dengan berbasis android agar dapat dengan mudah diakses oleh pengguna. 
Nama penulis : Zilzi Zade Tazkia

Judul : Perancangan Sistem Informasi Akuntansi Laporan Keuangan Laba Rugi pada Restoran Eatboss Dengan Menggunakan PHP dan MySQL
Jurnal @ is The Best Vol. 04 No. 01. Juni 2019: Hal 426-440

P-ISSN: 2252-9853

E-ISSN: 2656-808X

\section{Daftar Pustaka}

[1] H. T. Sitohang, "SISTEM INFORMASI PENGAGENDAAN SURAT BERBASIS WEB PADA PENGADILAN TINGGI MED AN," J. Inform. Pelita Nusant., vol. 3, no. 1, pp. 6-9, 2018.

[2] D. Satria and E. Al, "PERANCANGAN SISTEM INFORMASI MANAJEMEN DATA KORBAN BENCANA BERBASIS MOBILE ANDROID," J. Ekon. Manaj. dan Akunt., vol. 3, no. 2, pp. 22-30, 2017.

[3] V. M. Imbang, W. Pontoh, and H. Gamaliel, "ANALISIS PERLAKUAN AKUNTANSI ATAS PENGELOLAAN BERAS SEJAHTERA PADA PERUM BULOG DIVRE SULAWESI UTARA DAN GORONTALO Veronika," J. Ris. Akunt. Going Concern, vol. 13, no. 3, pp. 381-389, 2018.

[4] R. D. M. and Supriyati, "Model Perancangan Sistem Informasi Akuntansi Budidaya Perikanan Berbasis SAK EMKM dan Android," vol. volume 3, 2018.

[5] S. Bahri, Pengantar Akuntansi. Yogyakarta: Andi, 2016.

[6] B. Sidik, Pemrograman Web dengan PHP7. Bandung: Informatika, 2017.

[7] B. Raharjo, Belajar Otodidak Membuat Database Menggunakan MySQL. Bandung: Informatika, 2011.

[8] I. G. ngurah Suryantara, Merancang Aplikasi Akuntansi dengan VB.Net. Jakarta: Elex Media Komputindo, 2014. 